\title{
Efecto del hidróxido de calcio sobre la brotación, tizón tardío y rendimiento en papa "Criolla"
}

\section{Effect of calcium hydroxide on tubers' sprout, late blight and yield of "Criolla" potato}

\author{
Luisa F. Cardona ${ }^{*}$, Jairo Castaño ${ }^{2}$ \\ Recibido para publicación: Marzo 29 de 2016 - Aceptado para publicación: Mayo 27 de 2016
}

\begin{abstract}
RESUMEN
Para evaluar nuevas estrategias de tratamiento de semillas-tubérculos de papa y manejo del Tizón tardío, Phytophthora infestans se evaluó el efecto del hidróxido de calcio micronizado $\left[\mathrm{Ca}(\mathrm{OH})_{2}\right]$ sobre papa criolla. El estudio se realizó en la granja Tesorito de la Universidad de Caldas en un campo infestado por Phytophthora infestans. Se hicieron siete tratamientos: 1) Testigo, 2) Aplicación foliar de $\left.\mathrm{Ca}(\mathrm{OH})_{2}\left(4 \mathrm{~g} \mathrm{~L}^{-1}\right), 3\right)$ Aplicación foliar de $\mathrm{Ca}(\mathrm{OH})_{2}$ (8 $\left.\mathrm{g} \mathrm{L}^{-1}\right)$, 4) Aplicación foliar de $\left.\mathrm{Ca}(\mathrm{OH})_{2}\left(16 \mathrm{~g} \mathrm{~L}^{-1}\right) ; 5\right)$ Aplicación foliar de $\left.\mathrm{Ca}(\mathrm{OH})_{2}\left(32 \mathrm{~g} \mathrm{~L}^{-1}\right), 6\right)$ Tratamiento de semillas con metalaxil + mancozeb $\left(5 \mathrm{~g} \mathrm{~L}^{-1}+\right.$ aplicación foliar calendarizada de fungicidas, 7) Tratamiento de semillas con $\mathrm{Ca}(\mathrm{OH})_{2}$ ] $\left(4 \mathrm{~g} \mathrm{~L}^{-1}\right)+$ aplicación foliar calendarizada de fungicidas. El manejo del Tizón tardío se inició después de la brotación. Se empleó un diseño de bloques completos al azar, con cuatro repeticiones y 14 plantas efectivas por repetición. Se evaluó brotación de tubérculos $(\%)$, severidad del Tizón tardío (\%) y rendimiento $\left(\mathrm{t} \mathrm{ha}^{-1}\right)$. La mayor brotación se obtuvo tratando la semilla con $\mathrm{Ca}(\mathrm{OH})_{2}\left(4 \mathrm{~g} \mathrm{~L}^{-1}\right)$ o metalaxil + mancozeb $\left(5 \mathrm{~g} \mathrm{~L}^{-1}\right)$, ambos con un $92 \%$, evidenciando diferencias altamente significativas con los demás tratamientos. El rendimiento más alto se obtuvo tratando tubérculos con $\mathrm{Ca}(\mathrm{OH})_{2}+$ aplicación foliar calendarizada de fungicidas con 31,29 t $h^{-1}$. La severidad del Tizón tardío fue influenciada por la precipitación acumulada de 85,2 $\mathrm{mm}$ entre septiembre 3 y 13 , coincidiendo con el cierre de las calles, las cuales constituyen condiciones favorables para el desarrollo de la enfermedad.
\end{abstract}

Palabras clave: severidad, tasa de desarrollo, fungicidas, tubérculo-semilla.

\begin{abstract}
To evaluate new strategies of seed treatment and management of late blight, the effect of micronized calcium hydroxide $\left.[\mathrm{CaOH})_{2}\right]$ on criolla potato was tested. The study was conducted the Universidad de Caldas, Tesorito's farm, in a field infested with Phytophthora infestans. The treatments were: 1) Control, 2) Foliar spray of $\left.\mathrm{CaOH})_{2}\left(4 \mathrm{~g} \mathrm{~L}^{-1}\right), 3\right)$ Foliar spray of $\left.\left.\mathrm{CaOH}\right)_{2}\left(8 \mathrm{~g} \mathrm{~L}^{-1}\right), 4\right)$ Foliar spray of $\left.\mathrm{Ca}(\mathrm{OH})_{2}\left(16 \mathrm{~g} \mathrm{~L}^{-1}\right), 5\right)$ Foliar spray of $\left.\mathrm{CaOH}\right)_{2}$ $\left(32 \mathrm{~g} \mathrm{~L}^{-1}\right)$, 6) Seed treatment with metalaxil + mancozeb (5 $\left.\mathrm{g} \mathrm{L}^{-1}\right)+$ calendarized foliar sprays of fungicides, 7) Seed treatment with $\mathrm{Ca}(\mathrm{OH})_{2}\left(4 \mathrm{~g} \mathrm{~L}^{-1}\right)+$ calendarized foliar sprays of fungicides. The management of late blight was initiated after the seeds sprouted. A complete randomized blocks design was used, with four replications and seven treatments with 14 effective plants per replication. The variables evaluated were: tubers sprout (\%), disease severity $(\%)$ and yield $\left(\mathrm{t} \mathrm{ha}^{-1}\right)$. The highest sprout was obtained treating the tubers with $\mathrm{Ca}(\mathrm{OH})_{2}\left(4 \mathrm{~g} \mathrm{~L}^{-1}\right)$, or with metalaxyl + mancozeb $\left(5 \mathrm{~g} \mathrm{~L}^{-1}\right)$, both with $92 \%$ of final sprouting, with highly significant differences to the other treatments. The highest yield was obtained when tubers were treated with $\mathrm{Ca}(\mathrm{OH})_{2}+$ calendarized foliar sprays of fungicides with $31.29 \mathrm{t} \mathrm{ha}^{-1}$. The severity of late blight was influenced by an accumulated precipitation of $85.2 \mathrm{~mm}$, registered between September 3rd and 13th, coinciding with the close of the foliage, which constitute favorable conditions for the development of the disease.
\end{abstract}

Key words: severity, disease development, fungicides, tuber-seed.

\footnotetext{
${ }_{1 *}$ Magister en Fitopatología. Programa de Maestría en Fitopatología. Facultad de Ciencias Agropecuarias. Universidad de Caldas, Manizales-Colombia. Dirección: Calle 65 No. 26-10. Correo electrónico: luisafernandacardona@gmail.com

${ }^{2}$ Profesor Titular. Facultad de Ciencias Agropecuarias. Universidad de Caldas, Manizales, Colombia. Correo electrónico: jairo.castano_z@ ucaldas.edu.co
} 


\section{INTRODUCCIÓN}

La papa criolla (Solanum phureja Juz. et Buk) es originaria de la zona andina de Colombia y Ecuador, donde se encuentra la mayor variabilidad de esta especie. Se produce entre los 1.800 y los 3.200 msnm; siendo óptimas para su cultivo las alturas comprendidas entre los 2.300 y los 2.800 msnm, lo que equivale a un rango de temperaturas promedio de $10{ }^{\circ} \mathrm{C}$ a $20{ }^{\circ} \mathrm{C}$. Requiere una precipitación promedio de $900 \mathrm{~mm}$ al año (Zapata et al. 2006).

Según registros de la Cadena Nacional de la Papa, en el año 2008 se cultivaron en Colombia alrededor de 138.315 ha de papa, con un rendimiento promedio de 18,38 $\mathrm{t} \mathrm{ha}^{-1}$; se calcula que la papa criolla representó cerca del 6,8\% del área cultivada en 2009 con un área nacional de 8.950 ha. En Colombia, la producción de papa para el año 2011 fue de 1.998.250 t con un rendimiento de 17,53 $\mathrm{t} \mathrm{ha}^{-1}$ (FAOSTAT 2011).

El cultivo de la papa criolla es tan susceptible al ataque de plagas y enfermedades como la papa común, por lo que es preciso tomar todas las medidas preventivas que estén al alcance del productor a fin de evitar sus efectos devastadores (Zapata et al. 2006).

Entre las prácticas de protección sanitaria está la desinfección de la semilla de papa en pre-almacenaje y pre-plantación con thiabendazole, carbendazim, mancozeb, azoxystrobin, entre otros. Estos tratamientos son alternativas para proteger heridas producidas durante la manipulación del tubérculo, tanto en cosecha, almacenamiento y/o selección y para evitar el ataque de enfermedades durante los primeros estados de desarrollo de las plantas causadas por patógenos presentes en el suelo. La desinfección de semilla de papa con los productos anteriormente nombrados, ha demostrado proteger las plantas principalmente de problemas tales como Rizoctoniasis
(Rhizoctonia solani Kuhn), Fusariosis (Fusarium spp.) y Sarna plateada (Helminthosporium solani Durieu \& Mont.). La desinfección no elimina patógenos que estén en el interior del tubérculo (Acuña y Cadiz 2011).

El Tizón tardío, causado por el Chromista Phytophthora infestans (Mont.) de Bary, es el factor más limitante de la producción de papa en casi todos los países cultivadores. La enfermedad puede destruir el follaje y los tallos en cualquier momento durante el crecimiento de las plantas, aunque también puede atacar los tubérculos. El Tizón tardío puede destruir totalmente todas las plantas de una zona de cultivo al cabo de una a dos semanas, cuando las condiciones climáticas son favorables y no se aplica ningún método de control. Se estima que las pérdidas mundiales ocasionadas por la enfermedad ascienden a 6,7 billones de dólares (Haas et al. 2009). Actualmente es la enfermedad más devastadora de la papa, por lo tanto el cultivo debe ser asperjado periódicamente con fungicidas para protegerlo del patógeno (León et al. 2007).

El manejo de la enfermedad se ha centrado en la aplicación de fungicidas como propineb, oxadixil, mancozeb, metalaxil, triadimefon, clorotalonil y oxicloruro de cobre (Vallejo y Estrada 2004). El metalaxil, del grupo de las fenilamidas, ha sido exitoso en el control de patógenos como $P$. infestans, por su efectividad y eficacia curativa a dosis bajas en condiciones de alta presión de la enfermedad, lo que hizo que fuera atractivo para los agricultores que explotaron su potencial al máximo, conllevando a la resistencia del patógeno al fungicida (Nuninger et al.1995).

El control químico, a pesar de su relativa eficiencia, tiene efectos negativos como la selección de individuos resistentes debido al uso continuo de ciertos ingredientes activos; la reducción o eliminación de especies benéficas, de enemigos naturales de los insectos plaga, 
tanto depredadores como parasitoides; la alta toxicidad de los productos a los operarios y la presencia de residuos en los alimentos (Maniania et al. 2008), sin mencionar los costos indirectos generados como la contaminación del aire, de las aguas subterráneas, la degradación del suelo y la pérdida de diversidad biológica (Skirvin y Fenlon 2001; Restrepo 2008). Una alternativa viable a los problemas derivados del uso excesivo de plaguicidas sintéticos es la aplicación de métodos que no atente contra la salud humana y del medio ambiente (Furtado et al. 2007; Brito et al. 2009).

La evolución de los sistemas de producción agraria ha llevado al empleo de métodos de control de plagas y enfermedades más racionales y menos perjudiciales para el medio ambiente (Del Busto et al. 2008). Por ejemplo, la utilización de hidróxido de calcio $\left[\mathrm{Ca}(\mathrm{OH})_{2}\right]$ es una práctica antigua en el control de plagas y desempeñó un papel importante entre 1867 y 1939, usado en mezcla con sulfato de cobre ácido para conformar el caldo bordelés, básicamente utilizado en los cultivos de papa y vid para el control de enfermedades fungosas foliares (MINAG 2004). El hidróxido de calcio tiene un gran potencial para utilizarse como biocida en la agricultura, debido a que tiene la ventaja de no ser fitotóxico, es económico y fácil de usar y es inocuo al medio ambiente y a los humanos. El hidróxido de calcio en dosis de 0,02 $\mathrm{g} \mathrm{L}^{-1}$ de agua puede tener diversas reacciones que influyen en la resistencia de las plantas al ataque de patógenos en general; además se puede emplear en la desinfección del tubérculo-semilla de papa y reemplazar a productos químicos como carbofuran, benomil, mancozeb y metalaxil, que elevan significativamente los costos de producción (MINAG 2004).

Con base en lo anterior, se evaluó el efecto del hidróxido de calcio micronizado mediante tratamiento de tubérculos o semillas de papa criolla (Solanum phureja) sobre la brotación, y la aplicación foliar sobre el control del Tizón tardío.

\section{MATERIALES Y MÉTODOS}

Localización. La investigación se realizó en la granja 'Tesorito' (propiedad de la Universidad de Caldas), ubicada a 2.340 msnm, latitud Norte: $5^{\circ} 2^{\prime}$, longitud Oeste: $75^{\circ} 27^{\prime}$, con temperatura promedio de $17,5^{\circ} \mathrm{C}$, humedad relativa del $78 \%$ y precipitación anual de $2.000 \mathrm{~mm}$.

Siembra en campo. Se sembraron parcelas de 5 $m$. lineales en surcos dobles con distancia entre surcos dobles de 0,6 $\mathrm{m} \times 0,35 \mathrm{~m}$ entre plantas y distancia entre parcelas de 1,2 $\mathrm{m}$.

Se evaluaron seis tratamientos más un testigo absoluto:

T1 - Sin tratamiento de tubérculos-semillas, ni tratamiento del follaje (testigo absoluto).

T2 - Sin tratamiento de tubérculos-semillas, aplicación foliar de hidróxido de calcio $4 \mathrm{~g} \mathrm{~L}^{-1}$ de agua.

T3 - Sin tratamiento de tubérculos-semillas, aplicación foliar de hidróxido de calcio $8 \mathrm{~g} \mathrm{~L}^{-1}$ de agua.

T4 - Sin tratamiento de tubérculos-semillas, aplicación foliar de hidróxido de calcio 16 $\mathrm{g} \mathrm{L}^{-1}$ de agua.

T5 - Sin tratamiento de tubérculos-semillas, aplicación foliar de hidróxido de calcio 32 $\mathrm{g} \mathrm{L}^{-1}$ de agua.

T6 - Tratamiento de tubérculos-semillas con metalaxil + mancozeb (5 $\mathrm{g} \mathrm{L}^{-1}$ de agua) + aplicación foliar calendarizada de fungicidas.

T7 - Tratamiento de tubérculos-semillas con hidróxido de calcio (4 $\mathrm{g} \mathrm{L}^{-1}$ de agua) + aplicación foliar calendarizada de fungicidas.

Se utilizó un diseño experimental en bloques completos al azar, con cuatro repeticiones y 14 plantas efectivas por repetición. 
Tratamiento de tubérculos-semillas. Dos días antes de la siembra se seleccionaron 112 tubérculos los cuales se sumergieron en una solución de 5 g de metalaxil + mancozeb por litro de agua (T6); así mismo, se seleccionaron otros 112 tubérculos y se sumergieron en una solución de $4 \mathrm{~g}$ de hidróxido de calcio micronizado por litro de agua (T7); los tubérculos se sumergieron durante $5 \mathrm{~min}$ en ambas soluciones, después fueron llevados a un cuarto con luz difusa para evitar su contacto directo con la luz solar.

Aplicación de tratamientos foliares. Las aplicaciones foliares de hidróxido de calcio (T2, T3, T4 y T5), de los fungicidas preventivos y curativos (T6 y T7) para el control del Tizón tardío se iniciaron inmediatamente después de que los tubérculos brotaron, desde el 9 de agosto de 2013 y se continuaron cada 7 días, hasta el 1 de noviembre de 2013, en total se realizaron 14 aplicaciones. Para los tratamientos con hidróxido de calcio se prepararon soluciones de $4 \mathrm{~g}, 8 \mathrm{~g}, 16 \mathrm{~g}$ y $32 \mathrm{~g}$ por litro de agua y a cada una de ellas se le adicionaron $2 \mathrm{~mL} \mathrm{~L}^{-1}$ de agua del coadyuvante INEX-A. Los fungicidas utilizados se rotaron cada semana, así se rotó el ingrediente activo, esto con el fin de no generar problemas de resistencia por parte del Chromista. Al inicio de la brotación solo se aplicó preventivos, cuando aparecieron los primeros síntomas de la enfermedad se iniciaron aplicaciones con productos doble acción (sistémicos + preventivos).

Los fungicidas preventivos utilizados en el T6 y T7 fueron:

Clorotalonil (Fungitox $720 \circledR$ SC) $1 \mathrm{~L} \mathrm{ha}^{-1}$ Mancozeb (Dithaner ${ }^{\circledR} 60$ OF 0,75 L ha-1

Propineb (Fitoraz $\left.{ }^{\circledR W P} 76\right) 1,5 \mathrm{~kg}$ en $600 \mathrm{~L}$ de agua/ha

Los fungicidas curativos utilizados en el T6 y T7 fueron:

Propineb + fluopicolide (Trivia® WP) 1,2 kg ha $^{-1}$
Fosetil de Aluminio + mancozeb (Rhodax ${ }^{\circledR} 70$ WP) $2 \mathrm{~kg} \mathrm{ha}^{-1}$

Metalaxil + mancozeb (Ridomil $®$ Gold MZ 68 WP) $2 \mathrm{~kg} \mathrm{ha}^{-1}$

Fenamidone + propamocarb (Consento ${ }^{\circledR}$ SC) $1,5 \mathrm{~L} \mathrm{ha}^{-1}$

\section{Variables evaluadas}

Porcentaje de brotación. Se registró el número de tubérculos brotados por cada repetición; el porcentaje de brotación se obtuvo mediante la fórmula:

Brotación $(\%)=\frac{\text { Número de tubérculos brotados }}{\text { Número de tubérculos sembrados }} \times 100$

Severidad del Tizón tardío. Se evaluó cada 3 o 4 días en las primeras cuatro hojas de cuatro plantas por repetición y que presentaran síntomas de la enfermedad; las plantas y las hojas fueron identificadas para hacer seguimiento de la enfermedad hasta que las hojas alcanzaron el $50 \%$ de severidad, para lo cual se empleó el diagrama elaborado por James et al. (1971), el cual ilustra severidades de 1, 10, 25 y $50 \%$. Después de este valor, mediante extrapolación, se continuó registrando la severidad de la enfermedad hasta el $100 \%$.

Tasa de desarrollo del Tizón tardío (r). Se tomaron los valores promedios de severidad del Tizón tardío en las cuatro hojas evaluadas, siguiendo la metodología descrita por CastañoZapata (2002) y aplicando la siguiente fórmula:

$r=\frac{1}{T_{1}-T_{0}}\left(\log _{e} \frac{X_{1}}{1-X_{1}}-\log _{e} \frac{X_{0}}{1-X_{0}}\right)$

En donde, $r=$ Tasa de desarrollo, $\mathrm{T} 1=$ Tiempo final, T0 = Tiempo inicial, X1 = Proporción de la enfermedad en el tiempo final, $\mathrm{X} 0$ = proporción de la enfermedad en el tiempo inicial.

Rendimiento. La cosecha de los surcos en los tratamientos T1, T2, T3, T4 y T5, debido al nivel de infestación del Tizón tardío, se realizó a los 114 días después de siembra (8 
de noviembre de 2013) y la de los tratamientos T6 y T7, 7 días más tarde. Al momento de la cosecha se tomaron al azar 100 tubérculos de cada repetición y se clasificaron en cuatro categorías de calidad: primera (tubérculo con peso superior a $35 \mathrm{~g}$ ), segunda (peso promedio entre 25 g y $35 \mathrm{~g}$ ), tercera (peso promedio entre 15 g y 25 g) y redrojo (peso inferior a $15 \mathrm{~g} \mathrm{o}$ deformes). Para el cálculo de rendimiento total se incluyó el peso del redrojo con lo cual los datos se expresaron en $\mathrm{t} \mathrm{ha}^{-1}$.

Análisis estadístico. Los datos obtenidos en las variables evaluadas fueron sometidos a un análisis de varianza y posteriormente a pruebas comparativas de promedios tipo Duncan al 5\% por medio del programa PROG GLM de SAS (SAS Institute Cary, N.C. 1992).

\section{RESULTADOS Y DISCUSIÓN}

Porcentaje de brotación. Los tratamientos de tubérculos-semillas con mancozeb + metalaxil (T6) y con hidróxido de calcio (T7), tuvieron una brotación del $92 \%$, superando en un $20 \%$ la brotación de los demás tratamientos (T1, T2, T3, T4 y T5) los cuales no tenían tratamiento de tubérculo-semilla; además, el tratamiento de los tubérculos-semilla con $\mathrm{Ca}(\mathrm{OH})_{2}$ (T7) fue igual de efectivo que el tratamiento con mancozeb + metalaxil (T6), de modo que el agricultor dispone con una nueva opción eficaz y económica para el tratamiento preventivo de tubérculos-semilla de papa. A este respecto, Ávila (2011) sugiere la utilización del $\mathrm{Ca}(\mathrm{OH})_{2}$ como un desinfectante de tubérculos en una dosis de $4 \mathrm{~g} \mathrm{~L}^{-1}$ de agua, tratamiento que no afecta los puntos de crecimiento de los brotes aunque éstos sean muy pequeños.

Severidad del Tizón tardío. El análisis de varianza mostró diferencias altamente significativas entre tratamientos para los valores de severidad del Tizón tardío en las distintas fechas de evaluación.
En el cultivo de la papa criolla los fungicidas preventivos más empleados son mancozeb, clorotalonil, propineb y oxicloruro de cobre (Zapata et al. 2006); los tres primeros, fueron utilizados en este estudio inmediatamente después de la brotación en los tratamientos T6 y T7, que tenían aplicación foliar de fungicidas; posteriormente, cuando se manifestaron los síntomas del Tizón tardío en estos mismos tratamientos, se inició la aspersión de fungicidas de doble acción, con lo cual se pudo reducir el avance de la enfermedad en comparación con los tratamientos que sólo tenían aspersiones de hidróxido de calcio en el follaje y el testigo absoluto. En este último, la aparición de los primeros síntomas de la enfermedad fue el 23 de agosto, 37 días después de la siembra (dds) y 15 días después de emergencia (dde), (iniciación de formación de tubérculos); mientras que en los cuatro tratamientos con aspersión al follaje de hidróxido de calcio (4 g, 8 g, 16 g y 32 g), los primeros síntomas se observaron a los 41 dds y 19 dde (iniciación de tubérculos); con metalaxil+ mancozeb y con hidróxido de calcio, aplicados como tratamientos a los tubérculos-semillas y seguidos por las aplicaciones calendarizadas de fungicidas, los síntomas de la enfermedad se observaron el 3 de septiembre, es decir a los 48 dds y 26 dde (Ilenado de tubérculos) (Figura 1). De ésta manera, la aspersión de fungicidas preventivos retrasó en 11 días la aparición de los síntomas del Tizón tardío, y la aplicación de hidróxido de calcio al follaje causó un retraso de 4 días; comparados con el testigo absoluto.

El retraso en la aparición de la enfermedad producido por el hidróxido de calcio en aspersión al follaje puede deberse a que el calcio es componente de la pared celular y está involucrado con la unión de las moléculas pépticas (Ferguson y Drobak, 1988). La unión del calcio como un pectato en la lámina media es esencial para fortalecer las paredes celulares y los tejidos de la planta (Marschner 1995), lo cual dificulta la penetración del hongo en las hojas. Además, una de las principales 
características del hidróxido de calcio es su pH de 12,8, que probablemente eleva la alcalinidad de los tejidos de la hoja a niveles que limitan la reproducción y sobrevivencia de bacterias, hongos, virus y nematodos, que no toleran $\mathrm{pH}$ 's superiores a 10 (Ávila 2011).

Aunque la temperatura y la humedad relativa no mostraron variaciones notables a través del tiempo (Figura 1), los valores registrados fueron favorables para el desarrollo del Tizón tardío (temperatura $=15,5{ }^{\circ} \mathrm{C}$ y humedad relativa $=$ $79 \%$ ). Agrios (2005), indica que los esporangios de $P$. infestans germinan liberando de tres a ocho zoosporas a temperaturas de 12 a $15{ }^{\circ} \mathrm{C}$, mientras que por encima de $15{ }^{\circ} \mathrm{C}$ germinan directamente mediante la producción de un tubo germinativo. La temperatura mínima de crecimiento es de $4{ }^{\circ} \mathrm{C}$, la óptima $20{ }^{\circ} \mathrm{C}$ y la máxima de $26{ }^{\circ} \mathrm{C}$, pero el desarrollo de la enfermedad es favorecido por tiempo frío $\left(16-21^{\circ} \mathrm{C}\right)$, nublado y húmedo, en el que continuamente se están formando nuevos esporangios (Erwin et al. 1996); además una pequeña fuente de inóculo en presencia de humedad relativa por encima del 95\% durante 12 h y una variedad susceptible, son suficientes para ocasionar e incrementar el efecto de la enfermedad (Zapata et al. 2006). Todas estas condiciones se dieron en este estudio, lo que indica la alta severidad de la enfermedad; sin embargo, la variable climática más importante para el inicio, desarrollo y progreso posterior del Tizón tardío fue la precipitación, esto sumado al estado fenológico del cultivo y a la aplicación foliar de fungicidas. Obsérvese por ejemplo, que hasta el 23 de agosto (iniciación de tubérculos), la precipitación acumulada fue de $33,1 \mathrm{~mm}$ y en el testigo absoluto los síntomas de la enfermedad se manifestaron por primera vez en esa fecha, con una severidad de $0,29 \%$ (Figura 1), pero en los tratamientos que recibieron aplicación foliar de fungicidas todavía la enfermedad no se había observado, lo cual evidencia el efecto de la aspersión foliar de fungicidas sobre el desarrollo de la enfermedad, ya que hasta la fecha indicada ya se habían acumulado $30 \mathrm{~mm}$ de agua durante 10 días continuos, que es lo requerido para que la enfermedad se manifieste, como lo indica el sistema predictivo de BLITECAST desarrollado en The Pennsylvania State University, Estados Unidos, bajo la dirección de Raymond A. Krause a principios de 1970, que interpreta los patrones de precipitación con temperaturas y alta humedad relativa que indican el potencial de epidemias del Tizón tardío (Mackenzie 1981; Krause et al. 1975).

A partir del 3 de septiembre se presentó un incremento en la severidad de la enfermedad en todos los tratamientos, el cual estuvo asociado con el aumento en la precipitación acumulada que fue de 85,2 mm entre el 3 y 13 de dicho mes (Figura 1), período en el que el cultivo se encontraba en Ilenado de tubérculos, que a su vez implica el cierre de las calles por el contacto de las hojas entre surcos vecinos, lo cual es favorable para el desarrollo de la enfermedad (Meier 2001; Bello y Pinzón 1997; Valbuena 2000).

La presencia constante de inóculo y la susceptibilidad de los cultivares comerciales a $P$. infestans, obligan al productor a un uso intensivo de fungicidas (Oyarzun et al. 2001). Los fungicidas más utilizados entre los sistémicos son cimoxanil, metalaxil, propamocarb y fosetil-Al. La mayoría de veces se utiliza un sistémico mezclado con uno de contacto (Zapata 2001), un ejemplo es el metalaxil + mancozeb (Ridomil Gold®). Desde el 13 de septiembre, se usaron productos sistémicos en rotación para los tratamientos T6 y T7 (con químicos). Durante los 14 días siguientes (13 al 27 de septiembre) la severidad del Tizón tardío no aumento considerablemente, esto estuvo asociado con una disminución en la precipitación (18,5 mm de lluvia acumulada); sin embargo, entre el 1 y el 4 de octubre la precipitación acumulada fue de 67,9 mm, los cuales fueron suficientes para causar un nuevo 

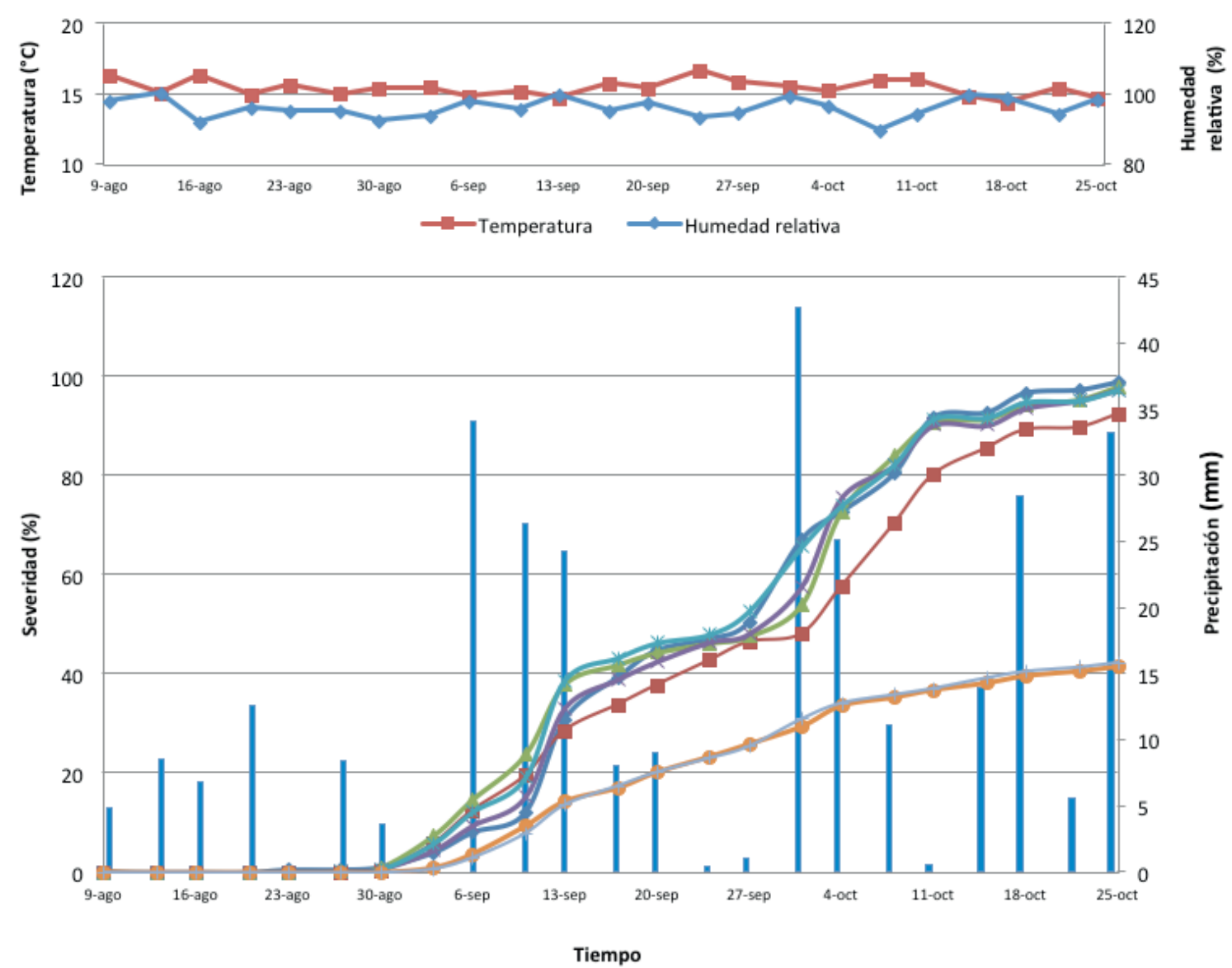

Figura 1. Relaciones entre algunos elementos del clima y la severidad del Tizón tardío a través del tiempo en función de los tratamientos empleados: $-4 \mathrm{~g} \mathrm{~L}^{-1} \mathrm{de} \mathrm{Ca}(\mathrm{OH})_{2}$ en aplicaciones foliares, $8 \mathrm{~g} \mathrm{~L}^{-1}$ de $\mathrm{Ca}(\mathrm{OH})_{2}$ en aplicaciones foliares, $16 \mathrm{~g} \mathrm{~L}^{-1} \mathrm{de} \mathrm{Ca}(\mathrm{OH})_{2}$ en aplicaciones foliares, $-32 \mathrm{~g} \mathrm{~L}^{-1}$ de $\mathrm{Ca}(\mathrm{OH})_{2}$ en aplicaciones foliares, — Tubérculos tratados con $\mathrm{Ca}(\mathrm{OH})_{2}$ y aplicaciones foliares de fungicidas, Tubérculos tratados con mancozeb + metalaxil y aplicaciones foliares de fungicidas, Testigo absoluto.

aumento en la severidad de la enfermedad, particularmente en los tratamientos $\mathrm{T} 1, \mathrm{~T} 2, \mathrm{~T} 3, \mathrm{~T} 4$ y T5, que no tuvieron aplicación calendarizada de fungicidas. Lo anterior demuestra la relación entre la precipitación y el desarrollo y avance de la enfermedad (Mackenzie 1981).

No obstante, obsérvese que hubo una tendencia que se conservó a través del tiempo, los valores de severidad siempre fueron menores en los tratamientos T6 y T7 que recibieron aplicación calendarizada de fungicidas, en comparación con los tratamientos con aspersiones foliares de hidróxido de calcio y el testigo absoluto (Figura 1), cuyos valores promedios el 3 de septiembre (48 dds - iniciación de formación de tubérculos) fueron de $4 \%$ para el testigo absoluto, $6 \%$ para los tratamientos con hidróxido de calcio en aplicación foliar y $1 \%$ para los tratamientos con aspersión foliar de fungicidas; los valores promedios de severidad correspondientes para el 27 de septiembre (72 dds - llenado de tubérculos) fueron: 50\%, 49\%, $31 \%$, respectivamente; y el 25 de octubre (100 
dds - madurez y cosecha) fueron: $99 \%, 97 \%$ y $42 \%$, respectivamente. Obsérvese, además, que el empleo del hidróxido calcio, que es un fertilizante, como compuesto antifúngico no causó efecto adverso sobre el desarrollo de la enfermedad, aunque sí retraso ligeramente, en 4 días, la aparición de los síntomas (Figura 1). Aunque en este estudio el hidróxido de calcio no muestra una acción, Noa (2006) afirma que es efectivo para controlar hongos y bacterias en plantaciones de fríjol, pepino, col, calabaza, pimiento, tomate y demás hortalizas. En experimentos in vitro con Aspergillus spp. se estableció que $2 \mathrm{~g} \mathrm{~L}^{-1}$ de agua de hidróxido de calcio, inhibió totalmente el crecimiento del hongo, al igual que la bacteria Rhizobium phaseoli cuyo crecimiento también fue inhibido por este producto en dosis de 3 y 4 g por litro de agua. De todas formas, es muy importante no generalizar la eficiencia del hidróxido de calcio contra las enfermedades porque como se estableció en el presente estudio, su acción contra el Tizón tardío estuvo muy por debajo de la lograda con fungicidas convencionales.

\section{Tasa de desarrollo del Tizón tardío (r)}

La tasa de desarrollo de la enfermedad (r) mostró dos tendencias de avance de la enfermedad: La primera, correspondió al testigo absoluto y a los tratamientos que recibieron aplicación foliar de hidróxido de calcio, con una tasa de desarrollo igual de $r=0,165$; la segunda, correspondió a los tratamientos que recibieron aplicación foliar de fungicidas que también fueron iguales entre ellos con $r=0,08$. Lo anterior indica que para lograr que el desarrollo de la enfermedad sea más lento, es indispensable realizar aspersión foliar de fungicidas.

Aunque la cal posee la capacidad de inhibir o detener el desarrollo y reproducción de hongos y bacterias que causan enfermedades a las plantas cultivadas, ya que actúa rompiendo las paredes celulares de bacterias y detiene la reproducción de hongos patógenos (Castro 2007), en este estudio no mostró capacidad inhibitoria después de la aparición de los primeros síntomas del Tizón tardío, siendo la tasa de desarrollo de los tratamientos con el hidróxido de calcio igual a la del testigo absoluto.

\section{Rendimiento}

El análisis de varianza mostró diferencias significativas y altamente significativas entre tratamientos para el número de tubérculos y el peso total y para el peso promedio de tubérculos, respectivamente.

El mayor rendimiento se obtuvo con el T7 (tratamiento de tubérculos-semillas con hidróxido de calcio (4 g L L $^{-1}$ de agua) + aplicación foliar calendarizada de fungicidas), el cual superó en un $15 \%$ el rendimiento obtenido en el T6 (tratamiento de tubérculos-semillas con metalaxil + mancozeb (5 $\mathrm{g} \mathrm{L}^{-1}$ de agua $)+$ aplicación foliar calendarizada de fungicidas), en un $83 \%$ al testigo absoluto y en un $79 \%$ al mejor de los tratamientos con hidróxido de calcio en dosis de $4 \mathrm{~g} \mathrm{~L}^{-1}$ de agua (Tabla 1). Nótese que todos los tratamientos foliares con hidróxido de calcio y el testigo absoluto

Tabla 1. Rendimiento en $\mathrm{t} \mathrm{ha} \mathrm{h}^{-1}$ en los diferentes tratamientos

\begin{tabular}{cc}
\hline TRATAMIENTO & $\begin{array}{c}\text { TONELADAS POR } \\
\text { HECTÁREA }\left(\mathbf{t ~ h a}^{-1}\right)\end{array}$ \\
\hline T1 & $5,26 \mathrm{C}^{*}$ \\
T2 & $6,53 \mathrm{C}$ \\
T3 & $4,60 \mathrm{C}$ \\
T4 & $4,61 \mathrm{C}$ \\
T5 & $4,65 \mathrm{C}$ \\
T6 & $26,58 \mathrm{~B}$ \\
T7 & $31,29 \mathrm{~A}$ \\
\hline
\end{tabular}

*Letras diferentes denotan diferencias significativas entre tratamientos según la prueba de rangos múltiples de Duncan al 5\%.

T1- Sin tratamiento de tubérculos-semillas, ni tratamiento del follaje (testigo absoluto, T2- Sin tratamiento de tubérculos-semillas, aplicación foliar de hidróxido de calcio $4 \mathrm{~g} \mathrm{~L}^{-1}$ de agua, T3- Sin tratamiento de tubérculos-semillas, aplicación foliar de hidróxido de calcio $8 \mathrm{~g} \mathrm{~L}^{-1}$ de agua, T4- Sin tratamiento de tubérculos-semillas, aplicación foliar de hidróxido de calcio $16 \mathrm{~g} \mathrm{~L}^{-1}$ de agua, T5- Sin tratamiento de tubérculossemillas, aplicación foliar de hidróxido de calcio $32 \mathrm{~g} \mathrm{~L}^{-1}$ de agua, T6Tratamiento de tubérculos-semillas con metalaxil + mancozeb $\left(5 \mathrm{~g} \mathrm{~L}^{-1} \mathrm{de}\right.$ agua) + aplicación foliar calendarizada de fungicidas, T7-Tratamiento de tubérculos-semillas con hidróxido de calcio (4 g L-1 de agua) + aplicación foliar calendarizada de fungicidas. 
tuvieron rendimientos inferiores a $7 \mathrm{t} \mathrm{ha}^{-1}$, valor que está muy por debajo del promedio nacional de 17,53 t ha-1 $^{-1}$ (FAOSTAT 2011).

Es importante resaltar la efectividad del hidróxido de calcio para el tratamiento al tubérculo-semilla, ya que con este tratamiento (T7) se obtuvieron 4,71 t más que cuando fueron tratados con metalaxil + mancozeb (T6); teniendo en cuenta que posteriormente el manejo del Tizón tardío fue el mismo para ambos tratamientos, las diferencia en producción puede ser atribuida al tratamiento con hidróxido de calcio al tubérculo-semilla, debido probablemente al efecto positivo que el calcio ejerce en el crecimiento inicial de las raíces ya que, como lo plantea Foy (1992), la ausencia de dicho elemento en el suelo retrasa el desarrollo de los ápices de las mismas, lo cual se debe al papel que este elemento desempeña en los procesos de división celular que tienen lugar en los ápices meristemáticos (Salisbury y Roos 1994).

El análisis de varianza para el número de tubérculos en las distintas calidades de comercialización mostró diferencias altamente significativas entre tratamientos. El mayor número de tubérculos de primera calidad se obtuvo cuando los tubérculos-semillas recibieron tratamiento y posteriormente aplicaciones foliares de fungicidas (T6 y T7), sin diferencia estadística entre ellos, pero sí con los tratamientos restantes. Esta misma tendencia se observó al analizar la respuesta en términos de las categorías de tamaño segunda y tercera. Al contrario, el tubérculo tipo redrojo fue más abundante en el testigo absoluto (T1) y en los tratamientos con aplicación foliar de hidróxido de calcio (T2, T3, T4 y T5), sin diferencia estadística entre ellos, pero sí con respecto a los dos tratamientos restantes (T6 y T7) (Tabla 2).

Siguiendo con la clasificación de las calidades, el análisis de varianza mostró diferencias altamente significativas entre tratamientos para el peso de los tubérculos de las cuatro categorías de calidad. De forma similar a como sucedió con la distribución del número de tubérculos en las categorías de tamaño, los tubérculos de mayor peso correspondieron a los tratamientos T6 y T7 en las categorías comercializables.

Tabla 2. Número de tubérculos en las distintas calidades de comercialización.

\begin{tabular}{crlcr}
\hline TRATAMIENTO & Primera & Segunda & Tercera & Redrojo \\
\hline T1 & $2 * \mathrm{~B}^{* *}$ & $2 \mathrm{~B}$ & $9 \mathrm{~B}$ & $87 \mathrm{~A}$ \\
T2 & $4 \mathrm{~B}$ & $4 \mathrm{~B}$ & $11 \mathrm{~B}$ & $81 \mathrm{~A}$ \\
T3 & $2 \mathrm{~B}$ & $2 \mathrm{~B}$ & $11 \mathrm{~B}$ & $85 \mathrm{~A}$ \\
$\mathrm{~T} 4$ & $2 \mathrm{~B}$ & $4 \mathrm{~B}$ & $10 \mathrm{~B}$ & $84 \mathrm{~A}$ \\
$\mathrm{~T} 5$ & $2 \mathrm{~B}$ & $4 \mathrm{~B}$ & $11 \mathrm{~B}$ & $83 \mathrm{~A}$ \\
T6 & $38 \mathrm{~A}$ & $18 \mathrm{~A}$ & $25 \mathrm{~A}$ & $19 \mathrm{~B}$ \\
$\mathrm{~T} 7$ & $44 \mathrm{~A}$ & $14 \mathrm{~A}$ & $21 \mathrm{~A}$ & $21 \mathrm{~B}$ \\
\hline
\end{tabular}

*Datos obtenidos de 100 tubérculos tomados al azar por repetición.

**Columnas con letras distintas denotan diferencias estadísticas según prueba Duncan al 5\%.

T1- Sin tratamiento de tubérculos-semillas, ni tratamiento del follaje (testigo absoluto, T2- Sin tratamiento de tubérculos-semillas, aplicación foliar de hidróxido de calcio $4 \mathrm{~g} \mathrm{~L}^{-1}$ de agua, T3- Sin tratamiento de tubérculos-semillas, aplicación foliar de hidróxido de calcio 8 v de agua, T4- Sin tratamiento de tubérculos-semillas, aplicación foliar de hidróxido de calcio $16 \mathrm{~g} \mathrm{~L}^{-1}$ de agua, T5- Sin tratamiento de tubérculos-semillas, aplicación foliar de hidróxido de calcio $32 \mathrm{~g} \mathrm{~L}^{-1}$ de agua, T6- Tratamiento de tubérculos-semillas con metalaxil + mancozeb (5 g L ${ }^{-1}$ de agua) + aplicación foliar calendarizada de fungicidas, T7- Tratamiento de tubérculos-semillas con hidróxido de calcio $\left(4 \mathrm{~g} \mathrm{~L}^{-1}\right.$ de agua) + aplicación foliar calendarizada de fungicidas. 


\section{CONCLUSIONES}

El hidróxido de calcio en una dosis de $4 \mathrm{~g} \mathrm{~L}^{-1}$ de agua fue muy efectivo como tratamiento desinfectante de tubérculo-semilla y se constituye en una opción para agricultor que tradicionalmente emplea productos fungicidas para tal fin. Este producto no afecta los puntos de crecimiento de los brotes aunque éstos sean muy pequeños.

El tratamiento preventivo de los tubérculos de papa con hidróxido de calcio puede considerarse un coadyuvante para el proceso de producción del cultivo, siempre y cuando este reciba aplicaciones frecuentes de fungicidas contra el Tizón tardío.

El hidróxido de calcio no afectó significativamente el desarrollo del Tizón tardío.

\section{REFERENCIAS}

Acuña, I. y Cadiz, F. 2011. Desinfección de tubérculo semilla de papa y sus consideraciones. Informativo Instituto de Investigaciones Agropecuarias. INIA Remehue, Informativo $N^{\circ}$ 84. Chile. 4p.

Agrios, G. 2005. Plant pathology. 5th Edition. Academic Press. New York, USA. 422p.

Ávila, H. 2011. Efecto biocida de la cal micronizada. eDiálogo. (En línea). Disponible en internet:http://www. edialogo.ning.com $/ \mathrm{m} / \mathrm{discussion?}$ id $=2703604 \% 3$ ATopic\%3A58341 diciembe 2013).

Bello, M. y Pinzón, B. 1997. Evaluación del efecto del tamaño del tubérculo tubérculo sobre el rendimiento de la papa criolla, variedad 'Yema de huevo' Solanum phureja Juz et Buk. Trabajo de grado. Facultad de Agronomía, Universidad Nacional de Colombia, Bogotá.
Britto E., Gondim, M., Torres, J., Fiaboe, K., Moraes, G. and Knapp, M. 2009. Predation and reproductive output of the ladybird beetle Stethorus tridens preying on tomato red spider mite Tetranychus evansi. BioControl 54: 363-368.

Castaño-Zapata, J. 2002. Principios básicos de fitoepidemiología. Centro Editorial Universidad de Caldas. Manizales, Colombia p 45, 210.

Castro, A. 2007. Prácticas alternativas para el manejo integrado de plagas y enfermedades. (En línea). Disponible en internet: http://www.promipac. org/promipaczamo/index 2 .php? option=com_docman\&task $=$ doc $_{-}$ view\&gid $=614 \&$ Itemid $=32 \quad$ (3 marzo 2011).

Del Busto, A., Santana, Y., Cruz, R., Leon, L., Hernandez, R. y Palomino, L. 2008. Efecto de la aplicación del hidróxido de calcio sobre enfermedades fungosas de Solanum lycopersicon L. (Tomate) en condiciones semicontroladas. Cuba. Disponible en linea: http:// www.monografias.com/trabajos-pdf3/ efecto-hidroxido-calcio-enfermedadesfungosas/efecto-hidroxido-calcioenfermedades-fungosas.pdf (18 octubre 2013).

Erwin, D. and Ribeiro, O. 1996. Phytophthora diseases worldwide, Ed. APS Press, St. Paul, MN, 347 p.

FAOSTAT. 2011. Agriculture. Statistics on crops. Core production data. http://faostat3.fao.org/home/index_ es.html? locale=es\#DOWNLOAD. (5 julio 5 2013).

Ferguson, I. and Drobak, B. 1988. Calcium and the regulation of plant growth and senescence. Hortscience 23: 262-266. 
Foy, D. 1992. Soil chemical factors limiting plant root growth. Advances in Soil Science 19: $97-149$.

Furtado, P., Moraes, J., Kreiter, S., Tixier, M. and Knapp, M. 2007. Potential of a Brazilian population of the predatory mite Phytoseiulus longipes as a biological control agent of Tetranychus evansi (Acari: Phytoseiidae, Tetranychidae). Biological Control 42(2):139-147.

Haas, B., Kamoun, S., Zody, M.C., Jiang, R., Handsaker, R., Cano, L. and Grabherr, M. 2009. Genome sequence and analysis of the Irish potato famine pathogen Phytophthora infestans. Nature 461(7262):393-398.

James, W., Callbeck, L., Hodgson, W. and Shih, C. 1971. Evaluation of a method used to estimate loss in yield of potatoes caused by late blight. Phytopathology 61: 14711476.

Krause, R., Massie, L. and Hyre, R. 1975. Blitecast, a computarized forecast of potato late blight. Plant Dis. Rep. 59(2):95 $-98$.

León, G., Gómez, R. y García, A. 2007. Control de plagas y enfermedades en los cultivos. Grupo Latino Editores. Bogotá, p661662.

Mackenzie, D. 1981. Scheduling fungicide applications for potato late blight. Plant Disease 65(5):394-398.

Maniania, N., Bugeme, D., Wekesa, V., Delalibera, J. and Knapp, M. 2008. Role of entomopathogenic fungi in the control of Tetranychus evansi and Tetranychus urticae (Acari: Tetranychidae), pests of horticultural crops. Experimental and Applied Acarology. 46 p.
Marschner, H. 1995. Mineral nutrition of higher plants. 2nd.ed. London, Academic Press. 889 p.

Meier, U. 2001. Estadios de las plantas monoy dicotiledóneas. $\mathrm{BBCH}$ Monografía. Centro Federal de Investigaciones Biológicas para Agricultura y Silvicultura. 149 p.

Minag (Ministerio de Agricultura). 2004. Estrategias de producción fitosanitarias para las hortalizas. Departamento Programa de Defensa. La Habana, Cuba. $10 \mathrm{p}$.

Noa, C. 2006. Curar las plantas sin medicina. http://www.guerrillero.co.cu/ variados/2004/febrero/curarlas_1.htm. (20 noviembre 2013).

Nuninger, C., Steden, C. and Staud, T. 1995. The contribution of Metalaxyl-based fungicide mixtures to potato late blight control. En: Phytophthora infestans. Dowley, L., Bannon, E., Cooke, R. L., Keane, T. \& O'sullivan, E. Editorial Boole Press Ltd. Dublin, p122 - 129.

Oyarzun, P., Taipe, J. y Forbes, G. 2001. Phytophthora infestans su actividad y particularidades en el Ecuador. Perfil de País. En: Estado Actual del Manejo Integrado del Tizón (MIP-Tizón) en Países Andinos. 17 p.

Restrepo, F. 2008. Manejo integrado de los ácaros en ornamentales. Tres innovaciones en Floricultura. Ceniflores, p7-56.

Salisbury, F. y Ross, C. 1994. Fisiología vegetal. Cuarta Edición. Grupo Editorial Iberoamérica, S. A. de C. V. D.México D.F., p144 - 145. 
SAS. 1992. In: SAS Institute Cary, N.C. EE.UU. Version 9.0.

Skirvin, D. and Fenlon, J. 2001. Plant species modifies the functional response of Phytoseiulus persimilis (Acari: Phytoseiidae) to Tetranychus urticae Koch (Acari: Tetranychidae): implication for biological control. Bolletin of Entomological Research, 91(01):61-67.

Valbuena, B. 2000. Aspectos básicos sobre el crecimiento y desarrollo en el cultivo de la papa. Manejo integrado del cultivo de la papa en Colombia. Corporación Colombiana de Investigación Agropecuaria (Corpoica), Bogotá.
Vallejo, F. y Estrada, S. 2004. Producción de hortalizas de clima cálido. Universidad Nacional de Colombia. Sede Palmira. Ed. Feriva. Palmira. 94 p.

Zapata, J. 2001. Aspectos sobre el Tizón tardío en Colombia. Perfil de País. La Selva, Regional 4, CORPOICA. Rionegro, Antioquia, Colombia. 13 p.

Zapata, J., Navas, G., Tamayo, A. y Diaz, A. 2006. Manejo agronómico de la papa criolla para el procesamiento industrial. Boletín tecnico CORPOICA. Centro de investigacion La Selva. Rionegro, Antioquia-Colombia, p3, 4, 24. 